\title{
Does Police Intervention in Intimate Partner Violence Work? Estimating the Impact of Batterer Arrest in Reducing Revictimization
}

\author{
Hyunkag Cho \\ Dina J. Wilke
}

\begin{abstract}
A variety of societal interventions in intimate partner violence have been established for decades, including the police actively arresting perpetrators. However, it is difficult to find consistent study results to show if arrest is effective. Moreover, there are far fewer studies on victims than on perpetrators. This study utilized the National Crime Victimization Survey to examine if victims whose partners were arrested were less revictimized than those whose partners were not arrested. Results clearly showed that arrest of perpetrators was effective in reducing revictimization, controlling for victims' characteristics and the nature of violence incidents. Also, separated or divorced women showed the highest risk of revictimization. Comparisons with previous studies and implications on police policies are discussed.
\end{abstract}

Keywords: Intimate partner violence, domestic violence, criminal justice, police, revictimization

\section{INTRODUCTION}

Violence against women by their male intimate partners has been recognized as a serious social problem for decades. According to the National Violence Against Women Survey, approximately one quarter of women have been victimized by intimate partners in their lifetime compared with only $8 \%$ of men (Tjaden \& Thoennes, 2000). Victims of intimate partner violence (IPV) suffer severe physical, mental, and psychological consequences of violence (Goodman, Koss, \& Russo, 1993a, 1993b; Monahan \& O'Leary, 1999; Schumacher, Feldbau-Kohn, Slep, \& Heyman, 2001). More tragically, 33\% of the women killed in the U.S. in 2004 were murdered by their male partners (Fox, 2006).

A variety of societal interventions were established to address IPV throughout the 1970s and 1980s. Domestic violence shelters have provided supportive services for victims and their children such as a temporary safe refuge, childcare, and legal advocacy. Police departments have encouraged officers to arrest perpetrators, while prosecutors have proceeded with charges against batterers without victims' participation. Victim protection orders have been issued by courts to prevent batterers from being in close physical proximity to the victim, and voluntary- or court-ordered batterer treatment programs have been developed (Cho \& Wilke, 2005; Roberts \& Kurst-Swanger, 2002).

Historically, the police disregarded IPV as a private and family matter (R. Berk, Berk, Loseke, \& Rauma, 1983; Browne, 1995; Dobash \& Dobash, 1979; LaFree, 1981), and had taken "a do-nothing approach" by just "cooling off" the batterer (Roberts \& KurstSwanger, 2002, p. 103). More recently though, since IPV was recognized as a crime, the police moved from the traditional passive approach to IPV into taking a more active role

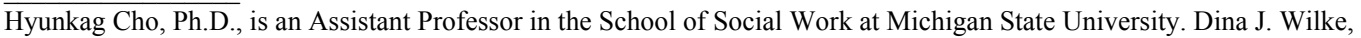
Ph.D., is an Associate Professor in the College of Social Work at Florida State University.

Copyright (C) 2010 Advances in Social Work Vol. 11 No. 2 (Fall 2010), 283-302 
in controlling it. Upon arriving at a reported domestic violence incident, the police are expected to arrest the batterer if necessary and provide victims with emergency aid and relevant information. Major intervention strategies of the police include warrantless arrest and pro-arrest policies which have increased arrest rates up to $70 \%$ from 1984 to 1989 following the implementation of pro-arrest policies (Baumer, Felson, \& Messner, 2003). When 111 grantees funded by the Arrest Policies Program established under the Violence Against Women Act of 1994 were reviewed, the arrest rates significantly increased across all grantees (Archer, DuPree, Miller, Spence, \& Uekert, 2003). Another study that looked at IPV incidence and arrest data from Maryland also found that the warrantless arrest policy had a significant positive impact on arrest likelihood (Simpson, Bouffard, Garner, \& Hickman, 2006).

The major theoretical framework supporting the arrest of batterers in response to IPV is deterrence theory. This theory contends that when police impose a meaningful reward or punishment (e.g., arrest) for IPV, batterers will be deterred from perpetration (Pate \& Hamilton, 1992; Salazar, Baker, Price, \& Carlin, 2003; Williams, 2005). Such deterrence is accomplished in two ways; specific deterrence and general deterrence (Gibbs, 1985; McGuire, 2002; Stafford \& Warr, 1993). Specific deterrence refers to "the deterrence of potential offenders who have been legally punished" (Gibbs, 1985, p. 88) or "effects on those who have suffered" (Stafford \& Warr, 1993, p. 123), and general deterrence refers to "the deterrence of potential offenders who have not been legally punished" (Gibbs, 1985, p. 88) or "effects on the general public" (Stafford \& Warr, 1993, p. 123). Deterrence is believed to occur when a potential offender avoids criminal behavior out of a desire to avoid the legal punishment of the behavior (Gibbs, 1985; Williams, 2005).

While arrest is supposed to affect batterers through deterrent effects, victims are also affected by arrest of the batterer. For instance, arrest may send a strong message to victims that domestic violence is a serious social problem and handled by the police seriously. Positive experiences with the police may lead victims to actively seek assistance from the police and others, which will increase their future safety and decrease revictimization. Another effect of arrest to victims would be the increased number of arrests of female victims along with male perpetrators (dual arrest; Finn, Blackwell, Stalans, Studdard, \& Dugan, 2004; Martin, 1997). It is not clear whether the increase resulted from women's increased perpetration of IPV, or reflects police officers' interpretations of pro-arrest policies. There may be loopholes in pro-arrest policies that may disadvantage victims rather than protecting them. If the victim were dissatisfied with, or disadvantaged by, the involvement of the police, victims would be less likely to report future IPV incident to the police and seek help from others, which may make victims more vulnerable to revictimization than before the police involvement. In this context, revictimization after arrest would be a good way to estimate the impact of arrest on victims.

It is difficult to find consistent study results to show if arrest is effective. While some argue that more batterers are arrested (Archer et al., 2003), others suggest that the police are still unwilling to arrest the batterer (Dugan, 2003). Some contend that police began to effectively control IPV as shown by reduced recidivism rates (Maxwell, Garner, \& Fagan, 2001), but others suggest that arrest has failed in deterring batterers from future violence, 
providing victims safety, and reducing incidents of IPV (Danis, 2003). One of the challenges facing social workers who serve a variety of clients affected by IPV-victims and perpetrators - is the lack of consensus on how the criminal justice system should deal with IPV. Social workers often find it hard to decide on the best actions to stop the perpetrator's abusive behaviors, ensure the victim's safety, and provide a better environment for their families (Danis, 2003). The current study attempts to fill this gap by using nationally representative data to examine whether victims would be less revictimized if the perpetrator were arrested, when compared with those whose partners are not arrested.

\section{REVIEW OF THE LITERATURE}

\section{Effects of Arrest on Batterers}

One of the most famous and influential studies on the effect of batterer arrest is the Minneapolis domestic violence experiment conducted from 1981 to 1982, the first randomized and controlled test of the effectiveness of arrest (Sherman \& Berk, 1984). A total of 314 cases were randomly assigned to one of three police choices; arresting the batterer and detaining him overnight ( $43 \%$ of 314 cases), separating the couple by having the batterer leave for eight hours (28\%), and just providing advice and information (28\%). Repeat offenses of each of three options were measured 6 months after the treatment both by official police records and victim interviews. The findings show that arrest was the most effective option as the recidivism rate for arrest cases was $10 \%$ based on official police records, compared with $19 \%$ for advice cases and $24 \%$ of separation cases. Recidivism rates based on victim interviews were somewhat different; $19 \%$ of the victims reported revictimization for arrest cases, $37 \%$ for advice cases, and 33\% for separation cases. These results significantly contributed to the nationwide adoption of active police policies.

Five replication studies of the Minneapolis experiment were conducted between 1985 to 1990. The first study was conducted in Omaha, NE, and overall experiment conditions were similar to the Minneapolis experiment (Dunford, Huizinga, \& Elliott, 1991). This study failed to find a statistically significant difference in recidivism rates among the three police choices. In Milwaukee, WI, cases were assigned to somewhat different police choices: arrest for 12 hours, arrest for 4 hours, or simple warning of future arrest (Sherman, Schmidt, Rogan et al., 1992). Recidivism rates for both arrest conditions were lower than a warning at 6 months, with no difference between the two types of arrest. However, there was no difference among three choices in recidivism rates 11 months later. A third study in Charlotte, $\mathrm{NC}$ also used somewhat different police options: providing advice or separating the couple, issuing a citation for court appearance, and arresting the batterer at the scene (Hirschel \& Hutchison, 1992). In this study, there was no significant deterrent effect of arrest. The fourth study conducted in Colorado Springs, $\mathrm{CO}$ utilized a large sample of 1,658 cases assigned to one of four options: emergency protective order only, emergency protective order and crisis counseling, emergency protective order and arrest, and restoring order at the scene (R. A. Berk, Campbell, Klap, $\&$ Western, 1992). While official police records showed no difference among the options, 
victim interviews found that arrest had deterrent effects. Further, police records showed that arrest had a slightly higher deterrent effect for employed batterers than those unemployed, although this was not confirmed through victim interviews. Finally, a study in Miami, FL involved two stages of police intervention; stage 1 compared arrest with no-arrest, and stage 2 compared a follow-up assignment to specialized service units with no follow-up (Pate \& Hamilton, 1992). Significant deterrent effects of arrest were found based on both police official records and victim interviews 6 months after the arrest. Arrested batterers showed a significantly lower recidivism rate $(15 \%)$ than those not arrested $(27 \%)$, but also fewer violent episodes than those not arrested. The follow-up services showed no difference in recidivism rates.

Clearly the results of studies on arrest are inconclusive. Methodological limitations may account for some of these results. Maxwell and colleagues (2001) attempted to control for some of these limitations by completing a meta-analysis of these studies. They reported that after pooling these studies and controlling for the differences, overall recidivism rates for arrested batterers were significantly less than those not arrested based on victim interviews, although no difference was found based on the police official record. While the empirical data are inconclusive, the ideological debate is heated. For example, opponents of arrest suggest that the assumption of an active police response to protect victims is largely an untested ideological assertion (Danis, 2003; Ford, 2003; Travis, 1998), and question the effect of arrest on long-term victim safety. Proponents of pro-arrest policies argue that the best way to address IVP is arrest, especially since no other police response is more effective (R. A. Berk, 1993), and the problem lies with lenient law enforcement and sentencing rather than arrest by itself (Baumer et al., 2003; Stark, 1996). Broadly speaking, it might be plausible to think that arrest cannot be studied independently because it is just one part of the broader criminal justice system (Gondolf, 2002).

\section{Effects of Arrest on Victims}

Research examining the relationship between arrest of batterers and victims' revictimization rarely includes victim characteristics. This may partly be related to concerns that, rather than establishing a context in which violence occurs, including victim-related variables in a study connotes blaming victims for the violence (Cattaneo \& Goodman, 2005). Nonetheless, several victim-related variables have been suggested as either predictors of revictimization or moderators of the relationship between arrest and revictimization, including age, race, marital status, educational attainment, and injury.

While age is often included in a list of control variables in studies of IPV, it does not appear to be a consistent predictor of revictimization (Cattaneo \& Goodman, 2005; Mears, Carlson, Holden, \& Harris, 2001). Some insisted that older women are more likely to be revictimized than the younger because they often stay in the abusive relationship due to low self-esteem, dependency, or fear of retaliation (Chaudhuri \& Daly, 1992; Ferraro, 1997; Flowers, 1996; Giles-Sims, 1983). Others contended that older women might have

more experience with IPV than the younger and more active in utilizing resources and services for victims to avoid revictimization (Klein, 1996). 
Race has been a controversial issue in IPV research, although IPV occurs across all races and ethnicities. Some research reported high victimization rates among racial minorities (Carlson, Harris, \& Holden, 1999; Mears et al., 2001). On the one hand, it may be because they reported IPV to the police more frequently than the White. The minority groups may have limited access to legal and socio-economic resources, and the police may be the only way for them to deal with IPV (S. L. Miller \& Wellford, 1997). On the other hand, it may be because of their experience of oppression. The minority groups may consider the police as "one of them" and be reluctant to report IPV to the police, which may make them vulnerable to IPV (Kingsnorth \& Macintosh, 2004; Sampson \& Wilson, 1995). However, one study reviewing sixty-four studies concluded that race and ethnicity were not associated with IPV victimization (Cattaneo \& Goodman, 2005). Overall, researchers have been cautious of proposing any relationship between race and IPV because it is hard to properly contextualize race within the overall social environment (Mears et al., 2001).

Studies that examine the relationship between the victim's marital status and revictimization are inconclusive. Some suggest that revictimization rates are higher for married victims because they cannot end the abusive relationship due to their lack of independence and personal power, which leads to the higher risk of revictimization (McCloskey, 1996), while others fail to show any relationship (Cattaneo \& Goodman, 2005). Educational attainment has been identified in many studies as being negatively related to revictimization (Cattaneo \& Goodman, 2005; Farmer \& Tiefenthaler, 2003; Schumacher et al., 2001; Tjaden \& Thoennes, 2000). Higher education attainment will be related to higher independent incomes and more access to economic resources, which will help victims take active coping strategies in dealing with violence (Rusbult \& Martz, 1995; Waldrop \& Resick, 2004). However, there are also studies showing that revictimization is positively associated with higher educational attainment (Wooldredge $\&$ Thistlethwaite, 2002).

Some studies reported no relationship between injury and revictimization (Holt, Kernic, Lumley, Wolf, \& Rivara, 2002), but others suggested that revictimization rates were less for victims suffering severe IPV incidents than others (J. L. Miller \& Krull, 1997). Victims of severe IPV may develop more active forms of behavioral coping skills (e.g., ending the violent relationship, seeking legal help, and avoiding potentially abusive new partners), which may reduce the risk of revictimization (Waldrop \& Resick, 2004). One study reported that revictimization rates decreased when the police arrested batterers seriously assaulting victims, which suggests that an effect of arrest may be greater for severe IPV (Harrel \& Smith, 1996).

There are, at least, two studies that utilized the national crime data to examine the relationship between reporting to the police and revictimization. Langan and Innes (1986) using the National Crime Survey (NCS) from 1978 to 1982 found that calling the police reduced subsequent assaults by $62 \%$ during a 6-month time period following an IPV incident. Felson, Ackerman, and Gallagher (2005) analyzed the National Crime Victimization Survey (NCVS) from 1992 to 2002. They found that not reporting to the police increased the odds of revictimization by $89 \%$, but the effect of arrest was 
statistically non-significant. No victim characteristics such as race, education, poverty or marital status were associated with revictimization.

Previous research did not succeed in yielding consistent results on the effectiveness of arrest, and focused mainly on the effects of arrest on batterers, ignoring effects on victims. Although the major beneficiary of arrest should be victims who are supposed to be safer after their partners could no longer perpetrate violence due to arrest, there are far fewer studies on victims than on perpetrators. Moreover, results from a few studies on victims are inconclusive. This study attempts to fill a gap by examining the effects of arrest on victims after controlling for several victim characteristics. Specifically, this study examines if, according to victim self-report, batterer arrest prevents revictimization after accounting for age, marital status, education and injury. It is expected that victims whose partners are arrested will experience lower rates of revictimization than those whose partners are not arrested.

\section{METHOD}

\section{Data}

This study used the National Crime Survey (NCS) from 1987 to 1992 combined with the NCVS from 1993 to 2003 . The NCS collected crime victimization information since 1973 and was replaced with the redesigned NCVS in 1992. The purpose of the survey's redesign was twofold. First, screening questions were enhanced to improve reporting of crime by stimulating respondents' recall. Second, additional questions were included to capture more about the nature and consequences of victimization (Kindermann, Lynch, \& Cantor, 1997). The NCS before 1987 did not collect data on arrest, and therefore was excluded from the analysis.

The U.S. Census Bureau conducts the NCS and the NCVS annually on behalf of the Bureau of Justice Statistics, gathering detailed crime data from a nationally representative sample of households that consist of about 100,000 individuals living in about 50,000 households. The dataset provides three levels of information; household-level, personlevel, and incident-level data. Further, each respondent in the sample is followed for three years, allowing the revictimization of individuals to be detected longitudinally. The NCVS asks respondents if they were criminally victimized during the previous six months. For each victimization incident, respondents are asked detailed questions including perpetrator arrest.

\section{Population and Sampling}

The target population of the analysis is women age 18 and over who reported being a victim of intimate partner violence. The sample for the NCVS was selected with a stratified, multi-stage, cluster design, and respondents are selected using a rotating panel sample design (U.S. Department of Justice, 2004). Households are randomly selected and all age-eligible individuals become part of the panel. Once in the sample, respondents are interviewed every six months for a total of seven interviews over a three year period. The first and fifth interviews are face-to-face; the rest are by telephone. After the seventh 
interview the household leaves the panel, and a new household is rotated into the sample. The NCS and NCVS have consistently obtained a response rate of about $95 \%$. Since this study was to examine if victims whose partners were arrested were revictimized less frequently than those whose partners were not arrested, the study sample consisted of respondents who reported being a victim in one interview and had been followed up for a year. The one year follow up was selected for two reasons. First, most of the previous experimental research examined recidivism rates 6 months to one year after the intervention (i.e., arrest). Using one-year follow-up rates would be most comparable to those studies. Second, a preliminary analysis of the original NCVS data before selecting the study sample showed that most revictimization (94\%) occurred within the first year following an IPV incident. Relatively few cases were missed, therefore, when limiting the follow-up period to one year thus maximizing sample size.

\section{Variables}

IPV is defined in the NCVS as a violent crime against women, including rape, sexual assault, robbery, aggravated assault, and simple assault, committed by a current or former male spouse or boyfriend (Catalano, 2008). As a result, this study includes only violence against women by men, excluding same sex couples, as there appear to be differences from heterosexual relationships that could influence arrest (Griffin, 2001; Island \& Letellier, 1991; A. J. Miller, Bobner, \& Zarski, 2000). Also, psychological and emotional violence are also excluded, for they are not usually considered by the police as criminal conduct, and the severity and degree of physical assaults and injuries are associated with judgment regarding arrest (Nicholls \& Dutton, 2001).

The study utilizes one dependent variable (revictimization), one independent variable (arrest), and six control variables (age, race, educational attainment, marital status, injury, and survey time). This study did not include other perpetrator-related information from the NCVS, such as offenders' age, race, alcohol or drug use, and use of a weapon, because the main interest of the study was in victims' characteristics.

Revictimization is defined as a woman being victimized a second time within one year following an IPV incident (this may include multiple partners), and is measured through self-report $(1=$ a victim was revictimized, $0=$ a victim was not revictimized $)$. Arrest is defined as the police taking a batterer into custody, and is also assessed according to the victim $(1=$ the police arrested the batterer, $0=$ the police did not arrest the batterer). The first control variable, age, is entered as a continuous variable. Race is a categorical variable with three categories; white as the omitted category, black, and others. Educational attainment is a categorical variable with three categories; less than high school diploma, high school diploma, and at least some post-secondary education as the omitted category. Marital status is a categorical variable that has five categories; married, widowed, divorced, separated, and never married as the omitted category. Injury is a categorical variable with three categories; minor injury (bruises, black eye, cuts, scratches, swelling, chipped teeth, and other injuries suffered), severe injury (gunshot wounds, knife wounds, internal injuries, broken bones, and knocked unconscious), and no injury as the omitted category. Finally, the instrument itself went through a redesign in changing from the NCS to the NCVS. In an effort to control for potential differences due 
to instrumentation, survey time was included in the analysis as a dichotomous variable $(0$ $=$ those who were first interviewed by the NCS, $1=$ those who were first interviewed by the NCVS).

\section{RESULTS}

\section{Sample Characteristics}

A total of 3,495 cases were included in the analysis; 1,162 from the NCS data (1987 to 1992) and the remaining 2,333 cases from the NCVS (1992 to 2003). A brief summary of sample characteristics is shown in Table 1. More than half of victims were widowed, divorced, or separated (51\%) and almost one third were never married (32\%). The majority of victims were white $(84 \%)$, followed by Black $(14 \%)$, and had a high school education or more $(81 \%)$. More than two thirds of victims were injured from an IPV incident $(70 \%)$. While the majority of injuries was minor, $8 \%$ of the victims reported severe injury. About one of five batterers (22\%) was arrested, while $18 \%$ of victims reported being revictimized. Finally, the mean age of victims was 31 .

\section{Table 1: $\quad$ Sample Characteristics}

\begin{tabular}{lrcr}
\hline Arrest & \multicolumn{3}{c}{ Revictimization } \\
Yes & $774(22 \%)$ & Yes & $620(18 \%)$ \\
No & $2,721(78 \%)$ & No & $2,875(82 \%)$ \\
Marital Status & & Educational Attainment & \\
Married & $603(17 \%)$ & Under high school & $669(19 \%)$ \\
Widowed & $42(1 \%)$ & High school & $1,415(41 \%)$ \\
Divorced & $871(25 \%)$ & Over high school & $1,411(40 \%)$ \\
Separated & $870(25 \%)$ & Race & \\
Never Married & $1,109(32 \%)$ & White & $2,919(84 \%)$ \\
Injury & & Black & $488(14 \%)$ \\
Minor & $2,167(62 \%)$ & Others & $88(2 \%)$ \\
Severe & $298(8 \%)$ & Age: Mean $=30.87 \mathrm{SD}=9.49$ & \\
No Injury & $1,030(30 \%)$ & & \\
\hline
\end{tabular}

\section{Logistic Regression Analysis Results}

The forced entry method was adopted for the logistic regression analyses as many researchers have recommended this method for theory testing (Studenmund, 2000, as cited in Field, 2000). Results of the logistic regression analysis are reported in Table 2. Arrest, age, marital status, and survey time were shown to have a significant impact on 
the odds of revictimization, while race, injury and educational attainment were nonsignificant.

As expected, arrest was shown to have a significant effect in preventing revictimization. The odds of revictimization for victims whose partners had been arrested were $43.2 \%$ less than those whose partners had not been arrested, after controlling for age, race, marital status, educational attainment, injury, and survey redesign $(\exp (\beta)=.568)$. Age had a small preventive effect on revictimization $(\exp (\beta)=.984)$. For each additional year, the odds of revictimization declined by $1.6 \%$. Revictimization rates varied depending upon marital status. Divorced or separated women were more likely to be revictimized than those never married $(\exp (\beta)=1.511$ and 1.525 , respectively). The odds of revictimization for separated women were $47.5 \%$ higher than unmarried women, and divorced women were $48.9 \%$ more likely than unmarried women to be revictimized. Finally, redesign of the survey from the NCS to the NCVS had an impact on revictimization reports. Victims who were interviewed using the NCVS showed odds of revictimization $45.8 \%$ greater than those interviewed with the NCS $(\exp (\beta)=1.458)$.

Table 2: $\quad$ Logistic Regression Analysis Summary

\begin{tabular}{|c|c|c|c|c|c|c|}
\hline & $\beta$ & S.E. & Wald & $d f$ & $p$-value & $\operatorname{Exp}(\beta)$ \\
\hline Arrest & -.566 & .104 & 29.815 & 1 & .000 & .568 \\
\hline Age & -.016 & .005 & 10.965 & 1 & .001 & .984 \\
\hline Race $^{1)}$ & & & 2.583 & 2 & .275 & \\
\hline Black & .269 & .363 & .548 & 1 & .459 & 1.308 \\
\hline Others & .023 & .391 & .003 & 1 & .953 & 1.023 \\
\hline Marital Status $^{2)}$ & & & 14.387 & 4 & .006 & \\
\hline Married & .228 & .129 & 3.120 & 1 & .077 & 1.256 \\
\hline Widowed & .171 & .409 & .175 & 1 & .676 & 1.186 \\
\hline Divorced & .413 & .166 & 6.182 & 1 & .013 & 1.511 \\
\hline Separated & .422 & .114 & 13.704 & 1 & .000 & 1.525 \\
\hline Injury ${ }^{3)}$ & & & .319 & 2 & .853 & \\
\hline Minor & -.044 & .079 & .312 & 1 & .577 & .957 \\
\hline Severe & -.015 & .163 & .008 & 1 & .929 & .986 \\
\hline Educational Attainment ${ }^{4)}$ & & & 2.574 & 2 & .276 & \\
\hline Under high school & -.120 & .125 & .908 & 1 & .341 & .887 \\
\hline High school & .078 & .097 & .653 & 1 & .419 & 1.081 \\
\hline Survey Time $e^{5)}$ & .377 & .176 & 4.599 & 1 & .032 & 1.458 \\
\hline
\end{tabular}

* Omitted category: 1) White, 2) Never married, 3) No Injury, 4) Over high school, 5) NCS 
A look at the cross-tabulation of arrest and revictimization may help to intuitively understanding the effect of arrest on revictimization (Table 3). Although the majority of victims were not revictimized regardless of arrest, $19.2 \%$ of victims whose partners had not been arrested were revictimized, compared to $12.7 \%$ of victims whose partners had been arrested.

Table 3: $\quad$ Cross-Tabulation of Arrest and Revictimization

\begin{tabular}{ccccc}
\hline & \multicolumn{2}{c}{ Was she revictimized? } & Total \\
& & Yes & No & \\
\hline Was he arrested? & Yes & $98(12.7 \%)$ & $676(87.3 \%)$ & $774(100 \%)$ \\
& No & $522(19.2 \%)$ & $2,199(80.8 \%)$ & $2,721(100 \%)$ \\
Total & & 620 & 2,875 & 3,495 \\
\hline
\end{tabular}

\section{DISCUSSION}

The logistic regression analysis of the effect of arrest on victims' chance of revictimization showed that arrest reduced the odds of revictimization by $43.2 \%$, after controlling for age, race, marital status, educational attainment, and injury. This result is consistent with results of some experimental studies (R. A. Berk et al., 1992; Pate \& Hamilton, 1992; Sherman \& Berk, 1984; Sherman, Schmidt, Rogan et al., 1992), and particularly with Maxwell et. al.'s (2001) meta-analysis of five replication studies on effects of arrest. The meta-analysis found that although official records showed no significant effect of arrest, victim interviews revealed that if batterers were arrested, recidivism rates were reduced by $25 \%$. Note that in the current study, the reduction of revictimization related to arrest was 39.6\%. Although direct comparisons of results between this study and Maxwell et al.'s might be inappropriate because of methodological differences (e.g., national survey sample versus local experimental samples), a conjectural comparison can be made for future research.

The difference in the size of arrest effect between 25\% for Maxwell et al., and 39.6\% for this study might result from the difference in the time frame when the two sets of data were collected. The five replication studies used in the Maxwell et al., study were conducted between 1985 to 1990 , while this study used the NCVS data from 1987 to 2003. Deterrence theory suggests that arrested batterers would be deterred by the punishment (specific deterrence), but potential batterers who have not been punished would not be affected much by an arrest unless they become aware of legal punishment for IPV (Gibbs, 1985) and avoid committing the offense (R. A. Berk \& Newton, 1985). Therefore, there would be a time lag before such a general deterrent effect could be realized. The arrest of batterers has steadily increased since the mid 1980s (Archer et al., 2003; Baumer et al., 2003), which in turn could suggest that through a general deterrent effect, there would be a time-lagged increase in size of arrest effect. While the specific deterrent effect of arrest is clearly shown by the study results, the general deterrent effect 
is less clear. One previous study attempted to measure the general deterrent effect by examining the temporal relationship between IPV incidence rates and arrest rates over time, and found the former decreased as the latter increased (Cho, 2007).

Table 4: $\quad$ Change in Arrest Effect Before and After 1990

\begin{tabular}{lcccccc}
\hline & $\beta$ & S.E. & Wald & $D f$ & $p$-value & $\operatorname{Exp}(\beta)$ \\
\hline Until 1990 (N=798) & -.142 & .321 & .196 & 1 & .658 & .868 \\
After 1990 (N=2,697) & -.627 & .160 & 15.334 & 1 & .000 & .534 \\
\hline
\end{tabular}

To explore the possibility of general deterrence, two separate logistic regression analyses were run using NCVS data through 1990 and after 1990, respectively (Table 4). From 1987 through 1990, arrest had no significant effect in preventing revictimization. After 1990, however, the odds of revictimization following arrest were $46.6 \%$ less than compared to those whose partners had not been arrested, when controlling for age, race, marital status, educational attainment, and injury $(\exp (\beta)=.534, p<.001)$. These results may suggest that the effect of arrest has increased over time, particularly since 1990, which may help to explain the difference in size of arrest effect between this study and Maxwell et al.'s meta-analysis. However, it must not be overlooked that the positive changes in IPV after 1990s may be the results of a variety of efforts to address IPV, including improvements both in services for IPV victims (e.g., shelters, children's program, and counseling programs) and in women's socio-economic status, the increased provisions of legal services for victims, and numerous state and federal laws enacted to address IPV, as well as the active police intervention (Cho \& Wilke, 2005; Farmer \& Tiefenthaler, 2003).

Another difference between this study and Maxwell et al.'s is a focus on revictimization versus recidivism rates. The current study examined arrest effect by revictimization rates and found these rates to be $12.7 \%$ for arrest cases and $19.2 \%$ for unarrested cases. However, Maxwell et al. used recidivism rates and found them to be $36 \%$ for arrest cases and $48 \%$ for unarrested cases, which were at least two times higher than our study. This difference might result partly from a variation in measurement. Recidivism in the Maxwell et al. study included reoffense committed only by the same batterer, while revictimization in the current study included reoffense by another batterer as well as the same one. It is not certain which one would show higher rates. Revictimization rates may be less than recidivism rates because the victim might have left the batterer after the violent episode so that reoffense by the previous partner would not have occured. In other words, victimization might have been transferred to another victim without being revealed. On the other hand, revictimization rates may be higher than recidivism rates because the former includes victimization from a new violent partner as well as the previous one. This possibility could not be tested with the NCVS because it did not distinguish the new partner from the previous one. Finally, the difference in revictimization rates between the two studies could also have resulted partly from different definitions of IPV which was defined more broadly in the Maxwell et al. 
study than it was in this study. While they included verbal threats of physical or property damage in addition to physical violence, this study included only physical violence. Consequently, revictimization rates in the current study should be less than recidivism in the Maxwell et al. study. Again, this possibility could not be further tested with the NCVS as it did not include verbal threat of property damage in the survey.

It is worth noting that the deterrent effect of arrest shown in this study was not found in a previous study that used a research method similar to this one. Felson et al. (2005) used the NCVS from 1992 to 2002 and found that reporting to the police, which was not included in this study, significantly reduced the odds of revictimization but arresting the batterer did not. For the purpose of comparison, reporting to the police was added as a independent variable to the analysis (data not shown). Similar to Felson et al. (2005), arrest did not have a significant effect on revictimization, but reporting to the police did. This indicates that reporting to the police and arrest have mostly overlapping impacts on revictimization, and arrest effects may be a subset of reporting effects. Future research is needed to further examine how reporting to the police interacts with arrest to lead to reducing revictimization.

In addition to finding that arrest has had an effect in reducing revictimization and that effect has increased over time, this study revealed other important aspects of an arrest effect; that is, the chance of revictimization varies according to characteristics of victims. Specifically, the victim's age and marital status were shown to have effects on revictimization, while race, educational attainment, and injury were not. The study found a negative relationship between age and odds of revictimization indicating that not only is lower age a significant predictor of victimization, but it predicts revictimization as well.

Regarding marital status, separated women showed the highest odds of revictimization, followed by divorced women, while married or widowed women were not different from the unmarried. These results did not support previous data which found higher revictimization rates for married women than unmarried women (McCloskey, 1996), or no relationship between a marital or cohabitation status and revictimization (Felson et al., 2005). One reason for the higher risk of revictimization for separated or divorced women may be their vulnerability to being contacted by their violent partners after separation. However, this possibility could not be tested as the NCVS data did not allow an examination of whether victims were separated or divorced after victimization, or whether they were revictimized by the same partner. While separated or divorced women have a higher risk of revictimization, requiring targeted prevention efforts for them, marital status alone may not be a good predictor of revictimization. For the quality and context of the relationship may play a greater role in IPV dynamics than the type of relationship between the batterer and victim (e.g., legal marital status, cohabitation, and dating; Cattaneo \& Goodman, 2005; Cole, Logan, \& Shannon, 2008). Given the mixed evidence with regard to the relationship between batterer and victim, future research may need to pay more attention to contextual factors of the interpersonal relationship than the status of relationship itself.

The NCS was replaced with the redesigned NCVS in 1992 to collect more accurate and detailed information of criminal victimization. In order to develop an adjustment 
factor that would be used to make two surveys comparable, half of the data were collected with the NCVS, and half were collected with the NCS for an 18-month period from 1992 to 1993. The NCVS has produced higher violent crime rates than the NCS after the adjustment was made (e.g., 50\% increase from 32 to 48 per 1,000 persons in 1992; Rand \& Catalano, 2007). The current study found $45.8 \%$ higher odds of revictimization for the victims interviewed using the NCVS compared to those interviewed with the NCS. Given that there is no known study to suggest a large increase in criminal revictimization after 1992, this study's result is likely a reflection of the higher crime rates produced by the redesigned survey.

\section{CONCLUSION}

This study found that arrest of batterers had an effect in reducing revictimization, which was different for different victims, providing support for the deterrent effect of arrest. The specific deterrent effect was realized when the chance of revictimization decreased after the batterer had been arrested by the police. Further, there may be some evidence to suggest a general deterrence effect as well, as there was an increase in the effect of arrest effect after 1992. However, these conclusions should be viewed within the context of the study's limitations. First, the overall effect of arrest will most likely be different according to the subsequent actions of the criminal justice system after arrest. However, this study did not examine those differences, but only considered characteristics of victims and IPV incidents. Some researchers have suggested that a particular intervention such as arrest cannot be isolated from other factors and truly be studied independently. Arrest is just one part of the broader criminal justice response that also includes prosecution, adjudication, probation, victims service, and other coordinated community services (Gondolf, 2002). To comprehensively understand the effect of arrest, future research needs to examine IPV victims from incident to arrest through prosecution to determine the effect of criminal sanction on a victim's long term safety.

This study examined the effect of arrest, controlling for victims' age, race, marital status, educational attainment, and injury, but did not control for other important victimrelated factors including income and employment. Consequently, differential effects of arrest according to different victims' characteristics could not be further examined. With all major victim-related factors included, future research can comprehensively examine in what conditions, and with whom, police intervention in IPV is most effective.

In addition, it should be noted that policies on IPV and police officers' implementation of them vary across police jurisdictions as well as states. However, this study could not control for those issues as the public-use NCVS does not provide any geographical information of respondents.

Finally, the data in the NCVS de-contextualizes a violent episode in that the level of fear or on-going intimidation in a relationship are not assessed, something that Johnson and Ferraro (2000) in their typology of IPV referred to as intimate terrorism. The Johnson and Ferraro typology also includes a classification referred to as common couple violence which is more minor in nature and can be perpetrated by either partner in a relationship. It may be that the low arrest and revictimization rates found in this study are related to 
the perpetration of common couple violence. However, that concern is somewhat moderated by the fact that $70 \%$ of respondents in this study indicated they were injured during the violent episode indicating a degree of severity.

Overall, this study demonstrated important relationships between arrest and revictimization. First, arresting batterers significantly reduced revictimization regardless of different victims' characteristics, and this effect has grown stronger over time. Proarrest policies have been questioned by some researchers on the grounds that arrest has no effect on repeat, unemployed batterers and therefore even increased the risk of revictimization for some victims (Hirschel \& Hutchison, 1992; Maxwell et al., 2001; Sherman, Schmidt, \& Rogan, 1992). The study results provide clear support for pro-arrest policies, although perpetrator characteristics were not examined.

Age has a negative relationship with revictimization, in that older victims have lower odds of being revictimized than younger victims. Also, considering separated or divorced women showed the highest risk of revictimization, strict enforcement of protective orders may be an important strategy for protection. Further, the lack of relationship between injury and revictimization indicates that police need to consider all available information in responding to a domestic violence call, and not over-emphasize one factor, such as injury.

The police have actively intervened in IPV since the 1980s. Many research results, including this study, support that police intervention helps in reducing revictimization of IPV. Along with other societal responses, police intervention may have contributed to a 52\% decline in IPV between 1993 and 2003 (Cho \& Wilke, 2005). Also, it might have contributed to the increase in IPV incidents reported to the police from $48 \%$ in 1993 to $60 \%$ in 2005 (Catalano, 2008).

While a great deal of work needs to be done to reduce IPV, the positive effect of police intervention, demonstrated by this study, is encouraging and provides several implications for social work research, practice, and policy. This study found that arrest effects varied, depending on the sociodemographic characteristics of the victims and, potentially, of the perpetrators. Future research needs to include information on both victims and perpetrators in examining the effects of perpetrator arrest on victims' future safety, and to identify factors that influence those effects. Social work practitioners will benefit from the research through an increased ability to make informed decisions that will better serve clients affected by IPV; client characteristics should be taken into consideration to judge whether those clients would be helped by certain types of criminal justice interventions. In this context, coordinated community intervention is particularly relevant to social work policy. This intervention model was developed in the 1980s, to better meet the needs of clients affected by IPV. It facilitates communication, and the sharing of resources and information among a variety of agencies in the community: the criminal justice system, social workers, and providers of health care and other human services (Pence \& McMahon, 1997; Pennington-Zoellner, 2010; Worden, 2001). Given that social workers have utilized a variety of collaboration models over the yearsincluding group work and community organization - social workers can play, and indeed have played, a critical role in community coordination (Saleebey, 2004). The current 
study results can be used to improve current procedures for coordinated community interventions and to develop new policies that can, in turn, address IPV more effectively.

\section{References}

Archer, C., DuPree, C., Miller, N., Spence, D., \& Uekert, B. (2003). National evaluation of the grants to encourage arrest policies program. Revised final report. Washington, DC: U.S. Department of Justice.

Baumer, E. P., Felson, R. B., \& Messner, S. F. (2003). Changes in police notification for rape, 1973-2000. Criminology, 41(3), 841-872.

Berk, R., Berk, S., Loseke, D., \& Rauma, D. (1983). Mutual combat and other family violence myths. In D. Finkelhor, R. J. Gelles, G. T. Hotaling \& M. A. Straus (Eds.), The dark side of families: Current family violence research (pp. 197-212). Beverly Hills, CA: Sage.

Berk, R. A. (1993). What the scientific evidence shows: On average, we can do no better than arrest. In R. J. Gelles \& D. R. Loseke (Eds.), Current controversies on family violence (pp. 323-336). Newbury Park, CA: Sage.

Berk, R. A., Campbell, A., Klap, R., \& Western, B. (1992). A Bayesian analysis of the Colorado Springs spouse abuse experiment. Journal of Criminal Law \& Criminology, 83, 170-200.

Berk, R. A., \& Newton, P. J. (1985). Does arrest deter wife battery? An effort to replicate the findings of the Minneapolis spouse abuse experiment. American Sociological Review, 50, 253-262.

Browne, A. (1995). Fear and the perception of alternatives: Asking "why battered women don't leave" is the wrong question. In B. Price \& N. Sokoloff (Eds.), The criminal justice system and women (pp. 228-245). New York: McGraw Hill.

Carlson, M. J., Harris, S. D., \& Holden, G. W. (1999). Protective orders and domestic violence: Risk factors for re-abuse. Journal of Family Violence, 4, 205-226.

Catalano, S. (2008). Intimate partner violence in the United States. Washington, DC: U.S. Department of Justice.

Cattaneo, L. B., \& Goodman, L. A. (2005). Risk factors for reabuse in intimate partner violence: A cross-disciplinary critical review. Trauma, Violence, \& Abuse, 6(2), 141175.

Chaudhuri, M., \& Daly, K. (1992). Do restraining orders help? Battered women's experience with male violence and legal process. In E. S. Buzawa \& C. G. Buzawa (Eds.), Domestic violence: The changing criminal justice response (pp. 227-252). Westport, CT: Auburn House.

Cho, H. (2007, January). Effects of arrest of batterers on reducing domestic violence incidence. Poster session presented at the $11^{\text {th }}$ annual meeting of Society for Social Work and Research, San Francisco. 
Cho, H., \& Wilke, D. J. (2005). How has the Violence Against Women Act affected the response of the criminal justice system to domestic violence? Journal of Sociology and Social Welfare, 32(4), 125-139.

Cole, J., Logan, T., \& Shannon, L. (2008). Women's risk for revictimization by a new abusive partner: For what should we be looking? Violence and Victims, 23(3), 315330.

Danis, F. S. (2003). The criminalization of domestic violence: What social workers need to know. Social Work, 48(2), 237-246.

Dobash, R. E., \& Dobash, R. P. (1979). Violence against wives. New York: The Free Press.

Dugan, L. (2003). Domestic violence legislation: Exploring its impact on the likelihood of domestic violence, police involvement, and arrest. Criminology \& Public Policy, 2(2), $283-312$.

Dunford, F. W., Huizinga, D., \& Elliott, D. (1991). The role of arrest in domestic violence assault: The Omaha experiment. Criminology, 28, 183-206.

Farmer, A., \& Tiefenthaler, J. (2003). Explaining the recent decline in domestic violence. Contemporary Economic Policy, 21(2), 158-172.

Felson, R. B., Ackerman, J. M., \& Gallagher, C. (2005). Police intervention and the repeat of domestic assault. Washington DC: U.S. Department of Justice.

Ferraro, K. J. (1997). Battered women: Strategies for survival. In A. P. Cardarelli (Ed.), Violence between intimate partners: Patterns, causes, and effects (pp. 124-143). Boston: Allyn \& Bacon.

Field, A. (2000). Discovering statistics: Using SPSS for Windows. Thousand Oaks, CA: Sage.

Finn, M. A., Blackwell, B. S., Stalans, L. J., Studdard, S., \& Dugan, L. (2004). Dual arrest decisions in domestic violence cases: The influence of departmental policies. Crime \& Delinquency, 50(4), 565-589.

Flowers, R. B. (1996). The problem of domestic violence is widespread. In K. L. Swisher (Ed.), Domestic violence (pp. 10-21). San Diego, CA: Greenhaven.

Ford, D. A. (2003). Coercing victim participation in domestic violence prosecutions. Journal of Interpersonal Violence, 18(6), 669-684.

Fox, J. A. (2006). Homicide trends in the United States. Washington, DC: U.S. Department of Justice.

Gibbs, J. P. (1985). Deterrence theory and research. In G. B. Melton (Ed.), The law as a behavioral instrument: Nebraska Symposium on Motivation 1985 (pp. 87-130). Lincoln, NE: University of Nebraska Press.

Giles-Sims, J. (1983). Wife battering: A systems theory approach. New York: Guilford. 
Gondolf, E. W. (2002). Batterer intervention systems: Issues, outcomes, and recommendations. Thousand Oaks, CA: Sage.

Goodman, L. A., Koss, A. P., \& Russo, N. F. (1993a). Violence against women: Mental health effects. Part II. Conceptualizations of posttraumatic stress. Applied and Preventive Psychology, 2, 123-130.

Goodman, L. A., Koss, A. P., \& Russo, N. F. (1993b). Violence against women: Physical and mental health effects. Part I. Research findings. Applied and Preventive Psychology, 2, 79-89.

Griffin, R. M. (2001, May 25). Breaking the silence: Sociologist studies woman-towoman sexual violence. Retrieved from http://www.gayhealth.com/templates/1117829363937302884179/common/feature.ht $\underline{\text { ml? record }=58}$

Harrel, A., \& Smith, B. (1996). Effects of restraining orders on domestic violence victims. In E. S. Buzawa \& C. G. Buzawa (Eds.), Do arrests and restraining orders work? (pp. 214-242). Thousand Oaks, CA: Sage.

Hirschel, J. D., \& Hutchison, I. W. (1992). Female spouse abuse and the police response: The Charlotte, North Carolina Experiment. Journal of Criminal Law \& Criminology, 83, 73-119.

Holt, V. L., Kernic, M. A., Lumley, T., Wolf, M. E., \& Rivara, F. P. (2002). Do protection orders affect the likelihood of future partner violence and injury? American Journal of Preventive Medicine, 24(1), 16-21.

Island, D., \& Letellier, P. (1991). Men who beat the men who love them: Battered gay men and domestic violence. New York: Haworth Press.

Johnson, M. P., \& Ferraro, K. J. (2000). Research on domestic violence in the 1990s: Making distinctions. Journal of Marriage and Family, 62, 948-963.

Kindermann, C., Lynch, J., \& Cantor, D. (1997). Effects of the redesign on victimization estimates (No. NCJ-164381). Washington, DC: U.S. Department of Justice.

Kingsnorth, R. F., \& Macintosh, R. C. (2004). Domestic violence: Predictors of victim support for official action. Justice Quarterly, 21(2), 301-328.

Klein, A. (1996). Re-abuse in a population of court-restrained male batterers: Why restraining orders don't work? In E. S. Buzawa \& C. G. Buzawa (Eds.), Do arrests and restraining orders work? (pp. 192-213). Thousand Oaks, CA: Sage.

LaFree, G. (1981). Official reactions to social problems: Police decisions in sexual assault cases. Social Problems, 28, 582-594.

Langan, P. A., \& Innes, C. A. (1986). Preventing domestic violence against women (No. NCJ-102037). Washington, DC: U.S. Department of Justice.

Martin, M. (1997). Double your trouble: Dual arrest in family violence. Journal of Family Violence, 12, 139-157. 
Maxwell, C., Garner, J., \& Fagan, J. (2001). The effects of arrest on intimate partner violence: New evidence from the Spouse Assault Replication Program. Research in brief. Washington, DC: U.S. Department of Justice.

McCloskey, L. A. (1996). Socioeconomic and coercive power within the family. Gender and Society, 10, 449-463.

McGuire, J. (2002). Criminal sanctions versus psychologically-based interventions with offenders: A comparative empirical analysis. Psychology, Crime, and Law, 8, 183208.

Mears, D. P., Carlson, M. J., Holden, G. W., \& Harris, S. D. (2001). Reducing domestic violence revictimization: The effects of individual and contextual factors and type of legal intervention. Journal of Interpersnal Violence, 16(12), 1260-1283.

Miller, A. J., Bobner, R. F., \& Zarski, J. J. (2000). Sexual identity development: A base for work with same-sex couple partner abuse. Contemporary Family Therapy, 22(2), 189-200.

Miller, J. L., \& Krull, A. C. (1997). Controlling domestic violence: Victim resources and police intervention. In G. K. Kantor \& J. L. Jasinski (Eds.), Out of the darkness: Contemporary perspectives on family violence (pp. 235-254). Thousand Oaks, CA: Sage.

Miller, S. L., \& Wellford, C. F. (1997). Patterns and correlates of interpersonal violence. In A. P. Cardarelli (Ed.), Violence between intimate partners: Patterns, causes, and effects (pp. 16-28). Boston: Allyn \& Bacon.

Monahan, K., \& O'Leary, K. D. (1999). Head injury and battered women: An initial inquiry. Health and Social Work, 24, 269-278.

Nicholls, T. L., \& Dutton, D. G. (2001). Abuse committed by women against male intimates. Journal of Couples Therapy, 10(1), 41-57.

Pate, A. M., \& Hamilton, E. E. (1992). Formal and informal deterrents to domestic violence: The Dade County spouse assault experiment. American Sociological Review, 57(5), 691-697.

Pence, E., \& McMahon, M. (1997). A coordinated community response to domestic violence. Duluth, MN: Duluth Domestic Abuse Intervention Project.

Pennington-Zoellner, K. (2010). Expanding 'community' in the community response to intimate partner violence. Journal of Family Violence, 24(8), 539-545.

Roberts, A. R., \& Kurst-Swanger, K. (2002). Police responses to battered women: Past, present, and future. In A. R. Roberts (Ed.), Handbook of domestic violence intervention strategies: Policies, programs, and legal remedies (pp. 101-126). New York: Oxford University Press.

Rusbult, C. E., \& Martz, J. M. (1995). Remaining in an abusive relationship: An investment model analysis of nonvoluntary dependence. Personality and Social Psychology Bulletin, 21, 558-571. 
Salazar, L. F., Baker, C. K., Price, A. W., \& Carlin, K. (2003). Moving beyond the individual: Examining the effects of domestic violence policies on social norms. American Journal of Community Psychology, 32(3/4), 253-264.

Saleebey, D. (2004). 'The power of place': Another look at the environment. Families in Society: The Journal of Contemporary Human Services, 85(1), 7-16.

Sampson, R. J., \& Wilson, W. J. (1995). Toward a theory of race, crime, and urban inequality. In J. Hagan \& R. D. Peterson (Eds.), Crime and inequality (pp. 37-54). Stanford, CA: Stanford University Press.

Schumacher, J. A., Feldbau-Kohn, S., Slep, A. M. S., \& Heyman, R. E. (2001). Risk factors for male-to-female partner physical abuse. Aggression and Violent Behavior, $6,281-352$.

Sherman, L. W., \& Berk, R. A. (1984). The specific deterrent effects of arrest for domestic assault. American Sociological Review, 49, 261-272.

Sherman, L. W., Schmidt, J. D., \& Rogan, D. P. (1992). Policing domestic violence: Experiments and dilemmas. New York: Free Press.

Sherman, L. W., Schmidt, J. D., Rogan, D. P., Smith, D. A., Gartin, P. R., Cohn, E. G., et al. (1992). The variable effects of arrest on criminal careers: The Milwaukee domestic violence experiment. Journal of Criminal Law \& Criminology, 83, 137-169.

Simpson, S. S., Bouffard, L. A., Garner, J., \& Hickman, L. (2006). The influence of legal reform on the probability of arrest in domestic violence cases. Justice Quarterly, 23(3), 297-316.

Stafford, M. C., \& Warr, M. (1993). A reconceptualization of general and specific deterrence. Journal of Research on Crime and Delinquency, 30, 123-135.

Stark, E. (1996). Mandatory arrest of batterers: A reply to its critics. In E. S. Buzawa \& C. G. Buzawa (Eds.), Do arrests and restraining orders work? (pp. 115-149). Thousand Oaks, CA: Sage.

Studenmund, A. H. (2000). Using econometrics: A practical guide $\left(4^{\text {th }}\right.$ ed.). Boston: Addison Wesley.

Tjaden, P., \& Thoennes, N. (2000). Extent, nature, and consequences of intimate partner violence: Research report. Washington DC: National Institute of Justice and the Centers for Disease Control and Prevention.

Travis, J. (1998). Civil protection orders: Victims' views on effectiveness. Research Preview. Washington, DC: National Institute of Justice.

U.S. Department of Justice, Bureau of Justice Statistics. (2004). NATIONAL CRIME VICTIMIZATION SURVEY, 1992-2002 [Computer file]. Conducted by U.S. Dept. of Commerce, Bureau of the Census. ICPSR ed. Ann Arbor, MI: Inter-university Consortium for Political and Social Research [producer and distributor]. 
Waldrop, A. E., \& Resick, P. A. (2004). Coping among adult female victims of domestic violence. Journal of Family Violence, 19(5), 291-302.

Williams, K. R. (2005). Arrest and intimate partner violence: Toward a more complete application of deterrence theory. Aggression and Violent Behavior, 10(6), 660-679.

Wooldredge, J., \& Thistlethwaite, A. (2002). Reconsidering domestic violence recidivism: Conditioned effects of legal controls by individual and aggregate levels of stake in conformity. Journal of Quantitative Criminology, 18(1), 45-70.

Worden, A. (2001). Models of community coordination in partner violence cases: A multi-site comparative analysis. Washington, DC: U.S. Department of Justice, National Institute of Justice.

\section{Author's Note:}

Address correspondence to: Hyunkag Cho, Ph.D., MSW, Assistant Professor, School of Social Work, Michigan State University, 254 Baker Hall, East Lansing, MI 48824.

Email: chohyu12@msu.edu 